\title{
LiXIVIAÇÃo de SUlFEnTRAZONe, IsOXAFlutole E OXYFlUORFEN NO PERFIL de TRÊS SOLOS ${ }^{1}$
}

\author{
Leaching of Sulfentrazone, Isoxaflutole and Oxyfluorfen in Three Soil Profiles
}

\author{
MELO, C.A.D. ${ }^{2}$, MEDEIROS, W.N. ${ }^{3}$, TUFFI SANTOS, L.D. ${ }^{4}$, FERREIRA, F.A. ${ }^{5}$, TIBURCIO, R.A.S. ${ }^{6}$ \\ e FERREIRA, L.R. ${ }^{7}$
}

\begin{abstract}
RESUMO - O destino de herbicidas aplicados em pré-emergência das plantas daninhas varia de acordo com o solo. Dessa forma, objetivou-se avaliar a lixiviação dos herbicidas sulfentrazone, isoxaflutole e oxyfluorfen no perfil de três solos. As doses de 0,5 e 0,75 kg ha-1 de sulfentrazone, 0,113 e 0,169 $\mathrm{kg} \mathrm{ha}^{-1}$ de isoxaflutole e 0,72 e 1,08 $\mathrm{kg} \mathrm{ha}^{-1}$ de oxyfluorfen foram aplicadas na superficie de colunas de PVC de $30 \mathrm{~cm}$ de altura preenchidas com três solos: um franco-arenoso e dois argilosos com teores alto (9,0 dag kg-1) e baixo (4,4 dag $\left.\mathrm{kg}^{-1}\right)$ de matéria orgânica. Após a aplicação, foram simuladas duas chuvas de $40 \mathrm{~mm}$ cada, com intervalo de 24 horas, respeitando o período de infiltração em cada solo. A lixiviação dos herbicidas ao longo do perfil dos solos foi verificada pelo método de bioensaio utilizando plantas de sorgo (Sorghum bicolor). A atividade herbicida do sulfentrazone e a movimentação no perfil dos solos foram elevadas na maior dose aplicada. A maior movimentação descendente do produto, na dose de $0,75 \mathrm{~kg} \mathrm{ha}^{-1}$ de sulfentrazone, foi constatada no solo de textura francoarenosa até $27,5 \mathrm{~cm}$, seguido pelos solos de textura argilosa com baixo e alto teor de matéria orgânica até 25 e 17,5 cm, respectivamente. Verificou-se elevado potencial de lixiviação do isoxaflutole, ultrapassando a profundidade de $22,5 \mathrm{~cm}$ nos três solos estudados e nas duas doses aplicadas, diferentemente do oxyfluorfen, que permaneceu adsorvido nas camadas superficiais dos solos. Ao comparar os solos, maior atividade herbicida e movimentação ocorreram naquele de textura franco-arenosa. Em relação aos herbicidas, o isoxaflutole apresentou maior mobilidade do que o sulfentrazone, enquanto o oxyfluorfen mostrou baixo potencial de lixiviação.
\end{abstract}

Palavras-chave: bioensaio, impacto ambiental, herbicida, mobilidade.

\begin{abstract}
The aim of this study was to evaluate herbicide leaching in three soil profiles.Doses of 0.50 and $0.75 \mathrm{~kg} \mathrm{ha}^{-1}$ sulfentrazone, 0.113 and $0.169 \mathrm{~kg} \mathrm{ha}^{-1}$ isoxaflutole, and 0.72 and $1.08 \mathrm{~kg} \mathrm{ha}^{-1}$ oxyfluorfen were applied on the surface of $30 \mathrm{~cm}$ high PVC columns filled with the three soil following types: one with a sandy loam texture and two clayey ones with low and high organic matter contents. After applying these herbicides, the columns were submitted to two rounds of 40 $\mathrm{mm}$ - simulated rain with a 24 hinterval between them. Herbicide leaching was detected by bioassay method using sorghum (Sorghum bicolor) plants. Both the activity and movement of the herbicide sulfentrazone in the soil profile increased after application of the highest dose. After application of $0.75 \mathrm{~kg} \mathrm{ha}^{-1}$ of sulfentrazone, the highest downward movement was observed in the sandy loam soil, down to $27.5 \mathrm{~cm}$, followed by the clayey soils with low and high organic matter contents, down to 25.0 and $17.5 \mathrm{~cm}$, respectively. A high leaching potential was observed of isoxaflutole, which exceeded $22.5 \mathrm{~cm}$ in depth for the three soils and both doses studied. However, oxyfluorfen remained adsorbed in surface layers of soil only. When comparing the types of soil, the highest herbicide activity and movement occurred in the sandy loam soil. Isoxaflutole presented greater mobility than sulfentrazone, while oxyfluorfen showed low leaching potential.
\end{abstract}

Keywords: bioassay, environmental impact, herbicide, mobility.

1 Recebido para publicação em 22.4.2009 e na forma revisada em 15.6.2010.

2 Graduanda em Agronomia, DFT/UFV, <chrisadinizmelo@yahoo.com.br>, bolsista IC/CNPq; ${ }^{3}$ Graduando em Agronomia, DFT/UFV; ${ }^{4}$ Professor Adjunto I da Universidade Federal de Minas Gerais - UFMG; ${ }^{5}$ Professor Titular do Dep. de Fitotecnia, DFT/UFV; ${ }^{6}$ Mestrando em Fitotecnia, DFT/UFV; ${ }^{7}$ Professor Adjunto, Dep. de Fitotecnia, Universidade Federal de Viçosa DFT/UFV, Av. P. H. Rolfs, s/n, 36570-000 Viçosa-MG.

Planta Daninha, Viçosa-MG, v. 28, n. 2, p. 385-392, 2010 


\section{INTRODUÇÃO}

O comportamento de um herbicida no solo é influenciado por processos de retenção, transformação e transporte. A mobilidade do herbicida no solo altera diretamente o seu desempenho no controle de plantas daninhas e sua dissipação no ambiente (Silva et al., 2007), constituindo-se numa variável relevante no estudo de impacto ambiental desses produtos.

O processo de lixiviação é a principal forma de transporte no solo das moléculas não voláteis e solúveis em água. Essas moléculas se movimentam no perfil do solo, acompanhando o fluxo de água, pela diferença de potencial entre dois pontos (Prata et al., 2003). A lixiviação apresenta dois aspectos importantes: é fundamental para incorporação superficial da maioria dos herbicidas, atingindo sementes ou plantas em germinação, mas, quando excessiva, pode carreá-los para camadas do solo mais profundas, limitando sua ação e podendo, inclusive, promover contaminação do lençol freático (Monquero et al., 2008). A lixiviação de herbicidas para camadas mais profundas pode aumentar o tempo de permanência dos produtos no ambiente, dada a menor atividade microbiológica (Sarmah et al., 1998; Prata et al., 2001).

A lixiviação potencial dos pesticidas no solo pode ser estimada por meio da percolação em colunas preenchidas com amostras deformadas ou indeformadas do solo, assim como por estudos em lisimetro. Entretanto, estudos sob condições de lisímetro são onerosos e, portanto, menos utilizados no Brasil. Assim, os estudos de lixiviação potencial no País restringem-se às colunas e aos modelos matemáticos (Prata et al., 2003).

Em estudos sobre atividade de moléculas herbicidas nos solos, pesquisadores têm utilizado o bioensaio, que alia baixo custo a bom resultado prático. Essa técnica consiste em utilizar plantas sensiveis aos produtos testados, de forma que residuos de herbicidas ou soluções presentes no solo possam ser evidenciados por meio da alteração das características agronômicas da planta-teste.

Na eucaliptocultura, o controle de plantas daninhas é feito basicamente pelo uso de herbicidas, sendo uma das alternativas a aplicação em pré-emergência de produtos como oxyfluorfen, isoxaflutole e sulfentrazone.

As características dos solos florestais, nos quais grande quantidade de resíduos e matéria orgânica é encontrada, podem influenciar a lixiviação e a ação de herbicidas aplicados em pré-emergência. Adicionalmente, o conteúdo e o tipo de argila e da matéria orgânica, a composição e a distribuição do tamanho das partículas, o pH, a densidade aparente e o tamanho e distribuição dos poros influenciam no comportamento e na ação desses produtos. $\mathrm{O}$ entendimento do efeito dessas características no comportamento de herbicidas pode levar à adequação de doses a características específicas do solo (Inoue et al., 2007). Para herbicidas de elevada capacidade adsortiva, o conteúdo de matéria orgânica do solo é geralmente um fator importante, pois, quanto mais alto, maior será a adsorção do herbicida e, com isso, menor a lixiviação. Em solos arenosos, a lixiviação será ainda maior do que em solos siltosos ou argilosos (Rossi et al., 2005).

Informações sobre a ação desses herbicidas em solos com características distintas são escassas e tornam-se relevantes para adoção de estratégias corretas para o manejo da cultura do eucalipto, bem como para determinação da viabilidade econômica e ambiental do uso desses produtos.

Diante do exposto, objetivou-se determinar o potencial de lixiviação dos herbicidas sulfentrazone, isoxaflutole e oxyfluorfen em três solos com diferentes características químicas e texturais.

\section{MATERIAL E MÉTODOS}

O experimento foi conduzido em ambiente protegido na Universidade Federal de Viçosa durante os meses de janeiro e fevereiro de 2008. O delineamento experimental adotado foi em blocos casualizados, com quatro repetições. Os tratamentos foram dispostos, para cada tipo de solo, em esquema fatorial $3 \times 2$, sendo três herbicidas (sulfentrazone, isoxaflutole e oxyfluorfen) e duas doses (dose recomendada pelo fabricante para a cultura do eucalipto $\mathrm{e}$ dose equivalente a $1+1 / 2$ da dose recomendada para cada produto). 
Os solos utilizados possuem características químicas e físicas distintas e foram provenientes de Viçosa, Virginópolis e Oratórios, municípios do Estado de Minas Gerais (Tabela 1), sendo dois solos argilosos com teores diferentes de matéria orgânica $\left(9,0\right.$ e 4,4 dag $\left.\mathrm{kg}^{-1}\right)$ e um solo franco-arenoso, respectivamente.

Colunas de PVC de $10 \mathrm{~cm}$ de diâmetro e $30 \mathrm{~cm}$ de altura foram revestidas internamente com parafina, a fim de diminuir a percolação da água pelas paredes das colunas, e devidamente montadas, sendo uma das extremidades (fundo) fechada por gaze e papel-filtro. Após o preparo, as colunas foram preenchidas com os três solos e, na posição vertical, receberam lâminas de água até que ocorresse percolação. Permitiu-se o escoamento da água durante 12 horas, para restaurar a capacidade de campo; após esse período, a aplicação do herbicida foi realizada. Utilizou-se um pulverizador costal com pressão constante mantida por $\mathrm{CO}_{2}$, acoplado a uma barra com um bico tipo leque TT11002, pressão de $250 \mathrm{Kpa}$, com volume de calda de $150 \mathrm{~L} \mathrm{ha}^{-1}$, para aplicação das doses de 0,5 e 0,75 $\mathrm{kg} \mathrm{ha}^{-1}$ de sulfentrazone, 0,113 e 0,169 $\mathrm{kg} \mathrm{ha}^{-1}$ de isoxaflutole e 0,72 e $1,08 \mathrm{~kg} \mathrm{ha}^{-1}$ de oxyfluorfen.

Imediatamente após a aplicação, as colunas foram colocadas sob simulador de chuva, onde receberam duas lâminas de água de $40 \mathrm{~mm}$ com intervalo de 24 horas, respeitando a velocidade de infiltração em cada solo. A duração de cada chuva (40 $\mathrm{mm}$ ) foi de 44, 23 e 20 minutos pra os solos de Oratórios, Viçosa e Virginópolis, respectivamente.

Decorridas 48 horas, as colunas de PVC tiveram suas extremidades fechadas e foram colocadas na posição horizontal sobre uma bancada. As colunas possuíam uma paleta lateral removivel, a qual foi retirada para a realização dos testes de germinação de sementes de sorgo - planta usada como bioindicadora da presença do herbicida. Na lateral do tubo foram feitas marcações de 2,5 em 2,5 cm eas sementes de sorgo semeadas uniformemente ao longo da coluna.

Avaliações de intoxicação foram realizadas aos 15 dias após a germinação, data em que as plantas foram também cortadas rente ao solo e acondicionadas em sacos de papel, para determinação da massa seca da parte aérea. $\mathrm{Na}$ avaliação de intoxicação utilizou-se uma escala, na qual as notas são referentes à porcentagem de área foliar afetada por injúrias ocasionadas pelo contato com o herbicida em relação à área foliar total da planta, em que $0 \%$ representa ausência de injúrias e $10 \%$ à morte da planta.

Para interpretação dos resultados, após a análise de variância a $5 \%$ de significância, utilizou-se a análise de regressão para os fatores quantitativos.

Tabela 1 - Resultados das análises química e física das amostras dos solos provenientes dos municípios de Viçosa, Virginópolis e Oratórios-MG

\begin{tabular}{|c|c|c|c|c|c|c|c|c|c|}
\hline \multicolumn{10}{|c|}{ Caracterização Química } \\
\hline \multirow{2}{*}{ Origem do Solo } & \multirow{2}{*}{$\mathrm{pH}$} & $\mathrm{P}$ & $\mathrm{K}$ & $\mathrm{AL}$ & $\mathrm{H}+\mathrm{Al}$ & $\mathrm{Ca}$ & $\mathrm{Mg}$ & \multirow{2}{*}{$\frac{\mathrm{MO}}{\left(\mathrm{dag} \mathrm{kg}^{-1}\right)}$} & \multirow{2}{*}{$\frac{\text { P-rem }}{\left(\mathrm{mg} \mathrm{L}^{-1}\right)}$} \\
\hline & & \multicolumn{2}{|c|}{$\left(\mathrm{mg} \mathrm{dm}^{-3}\right)$} & \multicolumn{4}{|c|}{$\left(\mathrm{cmol}_{\mathrm{c}} \mathrm{dm}^{-3}\right)$} & & \\
\hline Viçosa & 5,52 & 182,0 & 1.000 & 0,00 & 8,7 & 4,7 & 2,92 & 9,0 & 45,3 \\
\hline Virginópolis & 4,73 & 8,1 & 18 & 0,67 & 11,4 & 0,4 & 0,05 & 4,4 & 16,5 \\
\hline Oratórios & 5,84 & 12,4 & 110 & 0,00 & 4,1 & 1,2 & 0,58 & 0,4 & 37,7 \\
\hline \multicolumn{10}{|c|}{ Caracterização Física } \\
\hline \multirow{2}{*}{ Origem do Solo } & \multicolumn{2}{|c|}{ Argila } & Silte & Areia Fina & Areia $\mathrm{C}$ & & \multirow{2}{*}{\multicolumn{3}{|c|}{ Classe Textural }} \\
\hline & \multicolumn{6}{|c|}{$\left(\right.$ dag kg $\left.{ }^{-1}\right)$} & & & \\
\hline Viçosa & \multicolumn{2}{|c|}{56} & 8 & 16 & \multicolumn{2}{|c|}{20} & \multicolumn{3}{|c|}{ Argila } \\
\hline Virginópolis & \multicolumn{2}{|c|}{54} & 6 & 9 & \multicolumn{2}{|c|}{31} & \multicolumn{3}{|c|}{ Argila } \\
\hline Oratórios & 14 & & 14 & 47 & 25 & & \multicolumn{3}{|c|}{ Franco-Arenosa } \\
\hline
\end{tabular}

Análises realizadas nos Laboratórios de Análises Físicas e Químicas de Solo do Departamento de Solos da UFV. 


\section{RESULTADOS E DISCUSSÃO}

Maior atividade do sulfentrazone, avaliada pela intoxicação e inibição do crescimento das plantas de sorgo, foi observada no solo de textura franco-arenosa, em comparação aos outros dois solos que apresentam textura argilosa (Tabela 2 e Figura 1). Sua atividade herbicida e a movimentação no perfil dos solos foram elevadas na maior dose aplicada. A maior movimentação descendente do produto, na dose de $0,75 \mathrm{~kg} \mathrm{ha}^{-1}$ de sulfentrazone, foi observada no solo de textura franco-arenosa até $27,5 \mathrm{~cm}$, seguido pelos solos de textura argilosa com baixo e alto teor de matéria orgânica até 25,0 e $17,5 \mathrm{~cm}$, respectivamente (Figura 1).

De acordo com Vivian et al. (2006), a maioria dos residuos de sulfentrazone detectada em Argissolo Vermelho-Amarelo encontra-se na profundidade de $0-10 \mathrm{~cm}$, sendo baixo o potencial de lixiviação em solos argilosos. Segundo Bachega et al. (2009), em ensaio utilizando colunas de solo, bioensaio e três precipitações, a presença do sulfentrazone foi observada até a camada de $10 \mathrm{~cm}$ de um Latossolo Vermelho-Escuro mesmo com a maior precipitação $(106 \mathrm{~mm})$; contudo, esses autores observaram aumento do efeito fitotóxico do sulfentrazone com o aumento da precipitação. Também em trabalho sobre

Tabela 2 - Intoxicação de plantas de sorgo cultivadas ao longo de colunas, preenchidas com três solos, após a aplicação de duas doses de sulfentrazone e simulação de chuva

\begin{tabular}{|c|c|c|c|c|c|c|}
\hline \multirow{3}{*}{$\begin{array}{c}\text { Profundidade } \\
\text { no perfil do } \\
\text { solo (cm) }\end{array}$} & $\begin{array}{c}\text { Solo Franco- } \\
\text { Arenoso }\end{array}$ & $\begin{array}{c}\text { Solo Argiloso } \\
(\mathrm{MO}= \\
\left.4,4 \mathrm{dag} \mathrm{kg}^{-1}\right)\end{array}$ & $\begin{array}{c}\text { Solo Argiloso } \\
(\mathrm{MO}= \\
\left.9,0 \mathrm{dag} \mathrm{kg}^{-1}\right)\end{array}$ \\
\cline { 2 - 7 } & 0,5 & 0,75 & 0,5 & 0,75 & 0,5 & 0,75 \\
\hline & 8,50 & 9,75 & 7,00 & 6,75 & 7,75 & 9,00 \\
\hline 2,5 & 9,50 & 10,0 & 5,00 & 6,50 & 7,00 & 9,25 \\
\hline 5,0 & 9,50 & 10,0 & 3,67 & 6,00 & 6,25 & 9,00 \\
\hline 7,5 & 9,50 & 10,0 & 0,67 & 3,50 & 5,75 & 7,25 \\
\hline 10,0 & 9,25 & 10,0 & 0,67 & 3,25 & 3,75 & 6,00 \\
\hline 12,5 & 9,25 & 10,0 & 0,67 & 3,25 & 0,50 & 4,00 \\
\hline 15,0 & 8,25 & 10,0 & 0,33 & 2,25 & 0,00 & 0,75 \\
\hline 17,5 & 6,50 & 10,0 & 0,33 & 2,25 & 0,00 & 0,00 \\
\hline 20,0 & 1,00 & 8,33 & 0,33 & 2,75 & 0,00 & 0,00 \\
\hline 22,5 & 0,00 & 4,50 & 0,33 & 3,00 & 0,00 & 0,00 \\
\hline 25,0 & 0,00 & 0,25 & 0,33 & 3,00 & 0,00 & 0,00 \\
\hline 27,5 & & & & & & \\
\hline
\end{tabular}
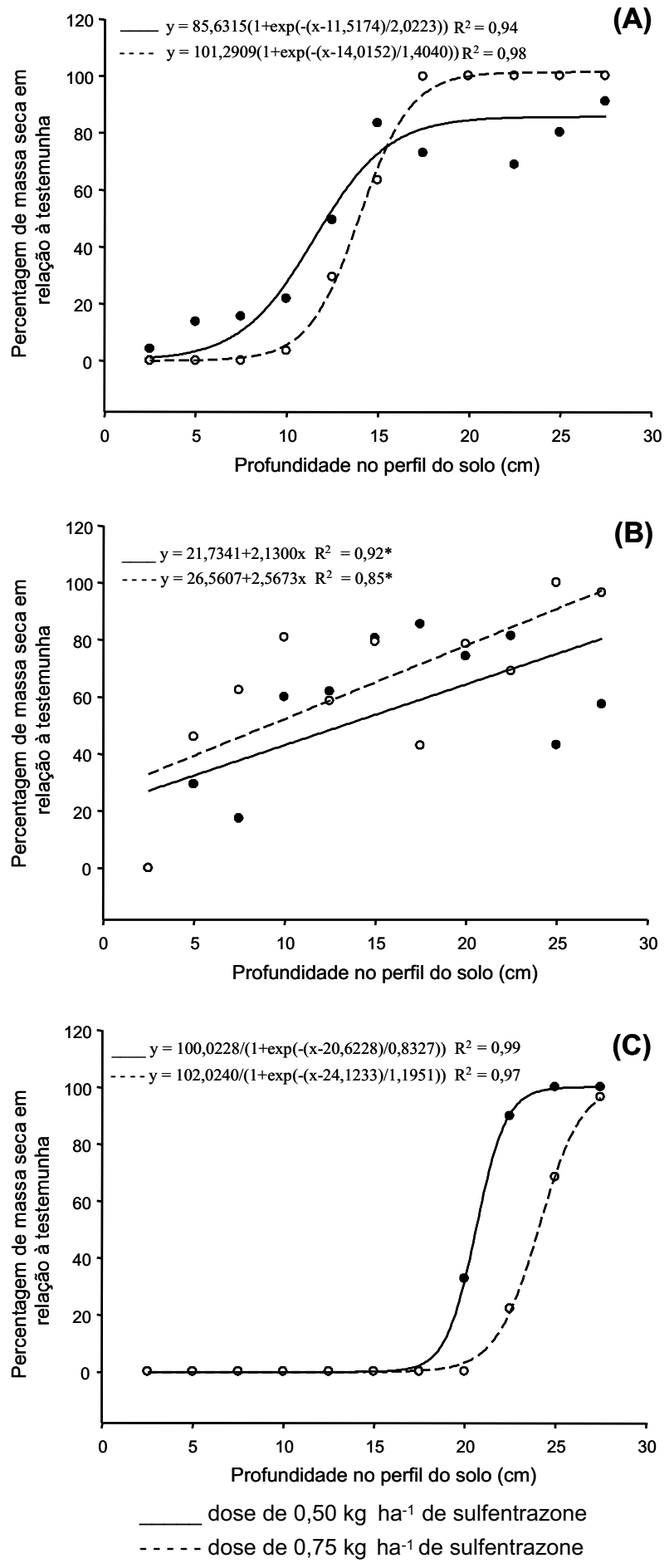

Figura 1 - Porcentagem de massa seca em relação à testemunha da parte aérea de plantas de sorgo cultivadas ao longo de colunas preenchidas com os solos de texturas argilosa com alto $\left(9,0\right.$ dag $\left.\mathrm{kg}^{-1}\right)$ teor de matéria orgânica (A), argilosa com baixo $\left(4,4 \mathrm{dag}_{\mathrm{kg}^{-1}}\right)$ teor de matéria orgânica (B) e francoarenosa (C), após a aplicação de sulfentrazone e simulação de chuva. 
mobilidade do sulfentrazone em função de diferentes índices pluviométricos, Rossi et al. (2005) encontraram em um Chernossolo (textura arenosa) uniformidade na distribuição do produto ao longo do perfil do solo $(30 \mathrm{~cm})$, proporcional à precipitação, enquanto no Latossolo Vermelho (textura argilosa) o produto foi pouco móvel, permanecendo na camada superficial $(2,5 \mathrm{~cm})$, independentemente da precipitação. Pelos resultados encontrados na literatura e observados no presente estudo, pode-se verificar que a intensidade da precipitação influencia diretamente a dinâmica e lixiviação do sulfentrazone no solo, a qual pode ser elevada nos casos de grande volume de água.

Na Figura 2, observa-se que no solo de textura franco-arenosa a movimentação descendente do isoxaflutole atingiu 25,0 e $22,5 \mathrm{~cm}$ para a menor e maior dose aplicada, respectivamente, embora tenha provocado sintomas decrescentes de intoxicação nas plântulas de sorgo de 0 a $27,5 \mathrm{~cm}$ (Tabela 3), fato que sugere o decréscimo da concentração do produto com o aumento da profundidade no perfil do solo.

Nos dois solos de textura argilosa, a produção de massa seca de sorgo em relação à testemunha foi afetada ao longo de toda a coluna nas duas doses aplicadas (Figura 2).

Tabela 3 - Intoxicação de plantas de sorgo cultivadas ao longo de colunas, preenchidas com três solos, após a aplicação de duas doses de isoxaflutole e simulação de chuva

\begin{tabular}{|c|c|r|c|c|c|c|}
\hline \multirow{3}{*}{$\begin{array}{c}\text { Profundidade } \\
\text { no perfil do } \\
\text { solo (cm) }\end{array}$} & $\begin{array}{c}\text { Solo Franco- } \\
\text { Arenoso }\end{array}$ & $\begin{array}{c}\text { Solo Argiloso } \\
(\mathrm{MO}= \\
\left.4,4 \mathrm{dag} \mathrm{kg}^{-1}\right)\end{array}$ & $\begin{array}{c}\text { Solo Argiloso } \\
(\mathrm{MO}= \\
\left.9,0 \mathrm{dag} \mathrm{kg}^{-1}\right)\end{array}$ \\
\cline { 2 - 7 } & 0,113 & 0,169 & 0,113 & 0,169 & 0,113 & 0,169 \\
\hline & \multicolumn{7}{|c|}{ Dose de Isoxaflutole $\left(\mathrm{kg} \mathrm{ha}^{-1}\right)$} \\
\hline 2,5 & 5,75 & 7,75 & 4,00 & 6,75 & 8,00 & 8,00 \\
\hline 5,0 & 6,75 & 8,25 & 4,00 & 4,00 & 7,00 & 6,50 \\
\hline 7,5 & 7,00 & 9,00 & 0,25 & 1,50 & 3,25 & 3,50 \\
\hline 10,0 & 7,00 & 10,00 & 0,00 & 0,00 & 2,25 & 2,25 \\
\hline 12,5 & 7,00 & 10,00 & 0,00 & 0,00 & 0,50 & 0,25 \\
\hline 15,0 & 7,00 & 9,50 & 0,00 & 0,00 & 0,25 & 0,25 \\
\hline 17,5 & 6,00 & 8,75 & 0,00 & 0,00 & 0,25 & 0,00 \\
\hline 20,0 & 5,00 & 7,50 & 0,00 & 0,00 & 0,00 & 0,00 \\
\hline 22,5 & 3,75 & 5,25 & 0,00 & 0,00 & 0,00 & 0,00 \\
\hline 25,0 & 2,00 & 1,50 & 0,00 & 0,00 & 0,00 & 0,00 \\
\hline 27,5 & 0,25 & 0,50 & 0,00 & 0,00 & 0,00 & 0,00 \\
\hline
\end{tabular}
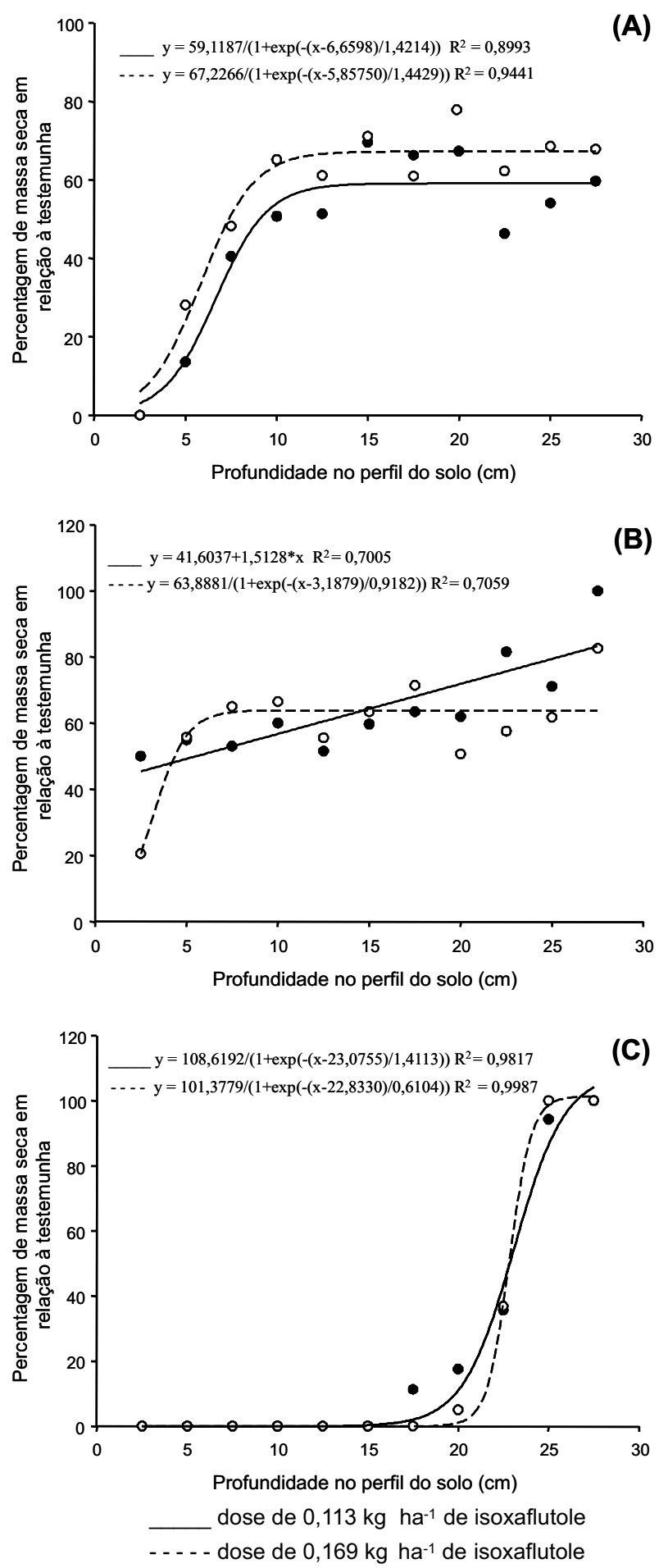

Figura 2 - Porcentagem de massa seca em relação à testemunha da parte aérea de plantas de sorgo cultivadas ao longo de colunas preenchidas com os solos de texturas argilosa com alto $\left(9,0\right.$ dag $\left.\mathrm{kg}^{-1}\right)$ teor de matéria orgânica (A), argilosa com baixo (4,4 dag $\left.\mathrm{kg}^{-1}\right)$ teor de matéria orgânica (B) e francoarenosa (C), após a aplicação de isoxaflutole e simulação de chuva. 
Na Tabela 3, nota-se que os sintomas de intoxicação no bioindicador foram observados até os 17,5 e $7,5 \mathrm{~cm}$ nos solos argilosos com alto e baixo teores de matéria orgânica, respectivamente. Resultado semelhante foi encontrado por Monquero et al. (2008), em cujo estudo o herbicida isoxaflutole aplicado em solo argiloso causou albinismo na parte aérea das plantas até 15 e $25 \mathrm{~cm}$ de profundidade no solo com chuvas de 10 e $80 \mathrm{~mm}$, respectivamente. Em solo com textura média, as maiores simulações de chuva (40 e $80 \mathrm{~mm}$ ) possibilitaram detectar esse herbicida em até $30 \mathrm{~cm}$.

Inoue et al. (2007), trabalhando com dois solos, um franco-arenoso e um argiloso, observaram comportamento diferenciado da movimentação de isoxaflutole, o que poderia estar relacionado à variação de carbono orgânico e, em menor grau, ao $\mathrm{pH}$ entre os solos. Segundo esses pesquisadores, quando foram aplicadas lâminas de chuva de 0 ou $20 \mathrm{~mm}$, observou-se comportamento semelhante em ambos os solos. Entretanto, a partir de $40 \mathrm{~mm}$ (LVd - textura franco-arenosa) ou de $60 \mathrm{~mm}$ (LRd - textura argilosa) de precipitação houve movimentação detectável para $5-10 \mathrm{~cm}$. Na precipitação de $80 \mathrm{~mm}$, a lixiviação do herbicida foi mensurável até a camada de $15-20 \mathrm{~cm}$ de profundidade. A sorção do isoxaflutole diminui com o decréscimo do teor de matéria orgânica do solo e é inversamente relacionada ao aumento do $\mathrm{pH}$ do solo, aumentando o potencial de lixiviação em solos mais próximos da neutralidade (Mitra et al., 1999).

De acordo com Sarmah et al. (1998) e Prata et al. (2001), a lixiviação de defensivos agrícolas no perfil do solo tem implicações diretas na contaminação de recursos hídricos do subsolo, pois, uma vez retirados das camadas superficiais, onde há maior teor de matéria orgânica e atividade microbiana, a sua persistência no ambiente pode ser intensamente prolongada. Assim, como foi observado elevado potencial de lixiviação para o isoxaflutole nos solos estudados, seu carreamento para camadas mais profundas do solo pode não só dificultar a degradação microbiana devido à limitação das condições favoráveis (umidade, temperatura, aeração, conteúdo orgânico e pH), aumentando sua persistência no sistema, como também promover seu transporte para região do solo pouco explorada pelas raízes das plantas daninhas, comprometendo a eficiência de controle.

Observa-se, na Figura 3, que o oxyfluorfen no solo franco-arenoso, quando aplicada a menor dose, afetou a produção de massa seca das plantas de sorgo em relação à testemunha somente nos primeiros $2,5 \mathrm{~cm}$ e na maior dose, ao longo de toda a coluna, apresentando, no entanto, $90 \%$ de produção de massa seca a partir dos $5 \mathrm{~cm}$. Nas avaliações de intoxicação, observou-se que no solo franco-arenoso não houve efeito nas plantas de sorgo presentes a partir de 5,0 e $10,0 \mathrm{~cm}$ de profundidade, na menor e maior dose aplicada, respectivamente (Tabela 4). No solo argiloso com alto teor de matéria orgânica, em ambas as doses, a massa seca das plantas de sorgo não foi afetada pelo oxyfluorfen em nenhuma profundidade, o que confirma a forte adsorção da molécula na matéria orgânica presente neste solo, permanecendo retida na superfície. Somente as plantas presentes nos primeiros $2,5 \mathrm{~cm}$ de profundidade apresentaram leves sintomas de intoxicação (Tabela 4).

No solo argiloso com baixo teor de matéria orgânica, o acúmulo de massa seca em relação à testemunha foi alterado somente até os $2,5 \mathrm{~cm}$ na menor dose e até $25 \mathrm{~cm}$ na maior dose aplicada (Figura 3), embora tenha apresentado sintomas de intoxicação apenas na maior dose até os $5 \mathrm{~cm}$ de profundidade (Tabela 4). Segundo Rodrigues \& Almeida (2005), o oxyfluorfen é um herbicida pouco solúvel em água $(<0,1 \mathrm{ppm}) \mathrm{e}$, por isso, dificilmente lavado ou lixiviado no solo, o que representa significativa vantagem nas regiões tropicais, onde altas precipitações são normais.

Yen et al. (2003) estudaram a dissipação e mobilidade do oxyfluorfen em diferentes solos sob diferentes condições de umidade e temperatura e concluíram que altas temperaturas aumentaram a taxa de dissipação. A possibilidade de contaminação de água subterrânea por oxyfluorfen é muito baixa, o que torna esse herbicida ambientalmente seguro quanto à percolação no perfil do solo.

As características físicas e químicas dos solos influenciaram a lixiviação dos herbicidas sulfentrazone, isoxaflutole e oxyfluorfen; a maior atividade herbicida e movimentação 

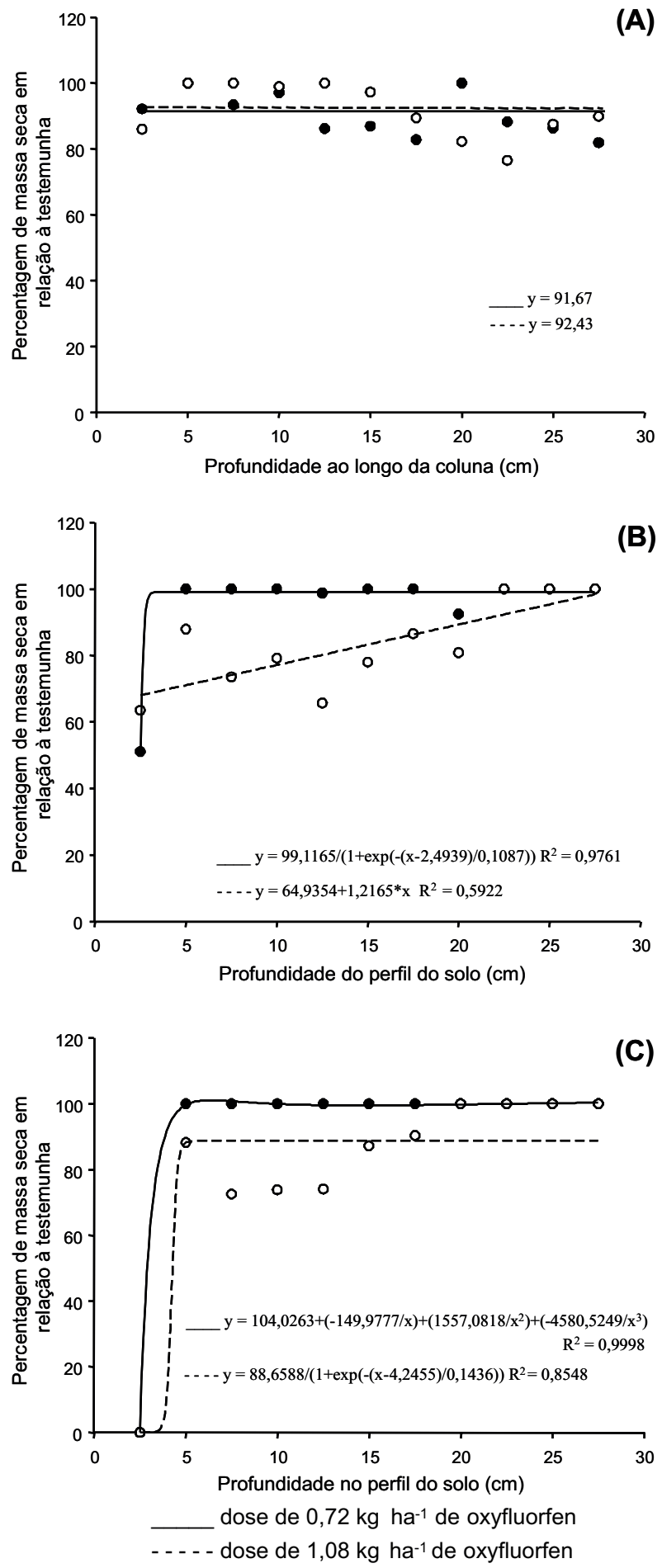

Figura 3 - Porcentagem de massa seca em relação à testemunha da parte aérea de plantas de sorgo cultivadas ao longo de colunas preenchidas com os solos de texturas argilosa com alto $\left(9,0 \mathrm{dag} \mathrm{kg}^{-1}\right)$ teor de matéria orgânica (A), argilosa com

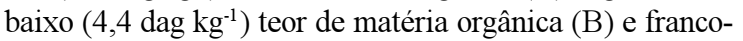
arenosa (C), após a aplicação de oxyfluorfen e simulação de chuva.

(A)

(B)

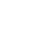

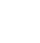

\section{AGRADECIMENTOS}

À Celulose Nipo Brasileira - CENIBRA e ao Conselho Nacional de Desenvolvimento Científico e Tecnológico - CNPq, pelo suporte financeiro.

\section{LITERATURA CITADA}

BACHEGA, T. F. et al. Lixiviação de sulfentrazone e amicarbazone em colunas de solo com adição de óleo mineral. Planta Daninha, v. 27, n. 2, p. 363-370, 2009.

INOUE, M. H. et al. Potencial de lixiviação de imazapic e isoxaflutole em colunas de solo. Planta Daninha, v. 25, n. 3, p. 547-555, 2007.

MONQUERO, P. A. et al. Potencial de lixiviação de herbicidas no solo submetidos a diferentes simulações de precipitação. Planta Daninha, v. 26, n. 2, p. 403-409, 2008.

MONQUERO, P. A. et al. Lixiviação de clomazone + ametryn, diuron + hexazinone e isoxaflutole em dois tipos de solo. Planta Daninha, v. 26, n. 3, p. 685-691, 2008.

Planta Daninha, Viçosa-MG, v. 28, n. 2, p. 385-392, 2010 
MITRA, S.; BHOWMILK, P. C.; XING, B. Sorption of isoxaflutole by five different soils varying in physical and chemical properties. Pestic. Sci., v. 55, p. 935-942, 1999.

PRATA, F. et al. Degradação e sorção de ametrina em dois solos com aplicação de vinhaça. Pesq. Agropec. Bras., v.36, n. 7, p. 975-981, 2001.

PRATA, F. et al. Glyphosate sorption and desorption in soils with different phosphorous levels. Sci. Agric., v. 60, n. 1, p. 175-180, 2003.

RODRIGUES, B. N.; ALMEIDA, F. S. Guia de herbicidas. Londrina: 2005. 591 p.

ROSSI, C. V. S.; ALVES, P. L. C. A.; MARQUES JUNIOR, J Mobilidade do sulfentrazone em Latossolo Vermelho e em chernossolo. Planta Daninha, v. 23, n. 4, p. 701-710, 2005.
SARMAH, A.; KOOKANA, R.; ALSTON, A. Fate and behaviour of triasulfuron, metsulfuron-methyl and chlorsulfuron in the Australian soil environment: A review. $\mathbf{J}$. Agric. Res., v. 49, n. 5, p. 775-790, 1998.

SILVA, A. A.; VIVIAN, R.; OLIVEIRA Jr., R. S. Herbicidas: comportamento no solo. In: SLVA, A.A.; SILVA, J.F., (Eds.). Tópicos em manejo de plantas daninhas. Viçosa, $\mathrm{MG}$ : Universidade Federal de Viçosa, 2007. p. 189-248.

VIVIAN, R. et al. Persistência de sulfentrazone em Argissolo Vermelho-Amarelo cultivado com cana-de-açúcar.

Planta Daninha, v. 24, n. 4, p. 741-750, 2006.

YEN, J. H.; SHEU, W. S.; WANG, Y. S. Dissipation of the herbicide oxifluorfen in subtrolical soils and its potential to contaminate groundwater. J. Ecotoxicol. Environ. Safety, v. 54, n. 2 , p. $151-156,2003$. 